\title{
Genetic and Environmental Influences on Verbal Aspects of Twins
}

\author{
Annu* and Bimla Dhanda \\ Department of Human Development and Family Studies, College of Home Science, \\ CCSHAU, Hisar-125004, India \\ *Corresponding author
}

\section{A B S T R A C T}

Keywords

Genetic,

Environment,

Verbal aspects,

Heredity

Article Info

Accepted:

12 October 2019

Available Online:

10 November 2019
Genes account for between approximately $50-60 \%$ variations in verbal abilities. Human genetic research aimed to characterize the genetic and environmental influence on verbal aspects namely information, vocabulary, similarities and comprehension of twins and correlation between monozygotic and dizygotic twins belonged to Bhiwani and Hisar district of Haryana State. Environmental influences were mainly of the non-shared variety, suggested that twins from the same family experience verbal differently. The result indicated that the correlation of monozygotic twins was more for information (0.79), vocabulary (0.74), similarities (0.61) and comprehension (0.62) in both districts namely, Bhiwani and Hisar. Twin study indicated that most verbal characteristics were heritable. Human genetic research also recognized the importance of environmental factors that also affect the verbal aspects of twins. The heritability estimates was used to assess the genetic influence on verbal abilities of twins. There was strong evidence that the heritability estimates of verbal abilities of twins ranges from 50 per cent to 60 per cent and the remaining 50 per cent to 40 per cent variance in verbal abilities of twins was accounted to environmental circumstances. Thus, the genetic pay more significant role in shaping the verbal abilities of twins.

\section{Introduction}

Heritability as the proportion of variation that arises from genetic influences. Genes are the suppliers of specific traits. Twins are nature's living laboratories. Twin studies have been a valuable source of information about the genetic basis of complex traits. The heritability studies with twin design contributed the most optimal estimation of genetic and environmental effects (Van
Dongen, et al., 2012). The heritability estimates from identical and fraternal twins are used to estimate the extent to which early genetic influences on cognition were amplified over time (Elliot et al., 2013). Most behavioural genetic studies have used the twin design for estimating heritability and environmentality through the comparison of monozygotic (MZ) and dizygotic (DZ) twin interclass correlations. 
Twin studies provide a framework to estimate heritable contributions between pairs of monozygotic twins, who share $100 \%$ of their genes, and dizygotic twins, who on average share $50 \%$ of their genetic endowment.

Identical (monozygotic) twins pairs showed closer similarities than nonidentical (dizygotic) twin pairs at later ages. The behaviour genetics emphasized the fact that the most important and influential genes vary at different age levels and genetic influences are of different importance at different ages.

Environment is the sum total of all the external conditions that affects an individual. It includes social, cultural and life experiences. When environments are homogeneous for all, all individual differences become heritable.

When there are both genetic and environmental differences, most of the mechanisms through which genes exert their causal influences on behaviour of twins. Though the study of heredity and environment, it was possible to estimate the extent to which differences between individuals for a trait can be attributed to genetic versus environmental factor or whether inter individual differences reflect variation in the environmental scores and/or the genetic scores. Further, there was evidence that genetic effects on patterns of brain change over time and the magnitude of relative genetic versus environmental influences may increase over the course of development (Anokhin et al., 2017).

\section{Materials and Methods}

\section{Location}

Present study was conducted in 37 villages from two districts of Haryana State namely; Hisar and Bhiwani.

\section{Observation recorded}

Only one observation on twins was completed to assess verbal aspects.

\section{Design}

The aim of twin study was to find out genetic and environmental influences on verbal aspects then the heritability estimate was worked out.

\section{Method}

Hundred pairs of twins in the age group of 6 to 8 years old were identified from selected villages on the basis of availability of twins.

The Z-test was applied to compare the mean scores of the twins from different districts and genetic influence was assessed with the help of heritability estimate.

\section{Tools}

The Wechsler Intelligence Scale for Children WISC-R (Wechsler, 1974) was used to assess child's cognition. This scale can be used on all child populations whether normal or abnormal of both sexes and of any socio-economic class. Home environment was measured with the help of Home Observation for Measurement of the Environment (HOME) Inventory by Bradley et al., (1988) for families with children ages 6 to 10 years. It measured aspects of the quantity and quality of social, emotional, and cognitive support made available to the child in the home environment

\section{Results and Discussion}

Correlation among monozygotic and dizygotic twins

Table 1 indicated that correlation among monozygotic twins was for information (0.79), 
vocabulary (0.74), comprehension (0.62) and similarities (0.61) in both districts namely, Bhiwani and Hisar. In dizyotic twins correlation was for information (0.51), vocabulary (0.48), comprehension (0.32) and similarities $(0.30)$ in both districts. The data clearly indicated that the monozygotic twins were more correlated in all behavioural aspects as compared to dizygotic twins.

Twins studies showed that identical twins have identical IQs since their genetic constitution is same, or it could be because they have the same experiences. A little bit variation in IQ could be attributed to different environmental factors. But in case of formation of dizygotic twins (DZ), genetically these twins are just like ordinary brothers and sisters, sharing 50\% genetic constitution, and they are only special in that they share the mother's womb (Mukherjee and Samanta 2017) (Fig. 1).

\section{Heritability estimates for behavioural aspects}

Table 2 indicated that genetic influences were an important source of variation in information, vocabulary and comprehension as heritability accounted for comprehension was highest (59.0\%) followed by information that was $57.0 \%$ and the heritability was lowest $(53.0 \%)$ for vocabulary. The heritability estimates indicated that the two behavioural aspects namely, information, comprehension of twins had more genetic influence than the only vocabulary had influence of environment and pertaining scope for improvement by improving social environment (Fig. 2).

Rosalind et al., (2018) reported that cognitive abilities of twins were heritable and observed that the genetic and environmental influences on different developmental patterns of verbal and non-verbal cognitive abilities of twins from the age group 7 to 12 years.

Spengler et al., (2018) investigated that genetic and environmental effects on verbal cognitive abilities of twins in the age of 7-14 years and reported that verbal cognitive ability and nonverbal ability indicated no significant interaction with parental education, while verbal abilities showed a significant interaction with parental education. The verbal abilities were more influenced by genetic factors.

Twin studies of diverse verbal characteristics are consistent in implicating the influence of genetic factors on individual differences in verbal abilities of twins. The twin study concluded that the influence of genetic was more on verbal abilities of twins as compared to environmental circumstances of twins. The verbal abilities of twins were partially heritable. The monozygotic twins were more correlated than the dizygotic twins in verbal aspects.

Human genetic research was also consistent in indicating genetic constitute the major source for shaping verbal abilities of twins.

Table.1 Correlation among monozygotic and dizygotic twins

\begin{tabular}{|c|c|c|c|c|}
\hline Twins & Information & Vocabulary & Comprehension & Similarities \\
\hline Monozygotic & 0.79 & 0.74 & 0.62 & 0.61 \\
\hline Dizygotic & 0.51 & 0.48 & 0.32 & 0.30 \\
\hline
\end{tabular}


Table.2 Heritability estimates for verbal aspects

\begin{tabular}{|c|c|}
\hline Verbal aspects & Heritability (\%) \\
\hline Information & 57 \\
\hline Vocabulary & 53 \\
\hline Comprehension & 59 \\
\hline Similarities & 58 \\
\hline
\end{tabular}

Fig.1 Correlation among monozygotic and dizygotic twins

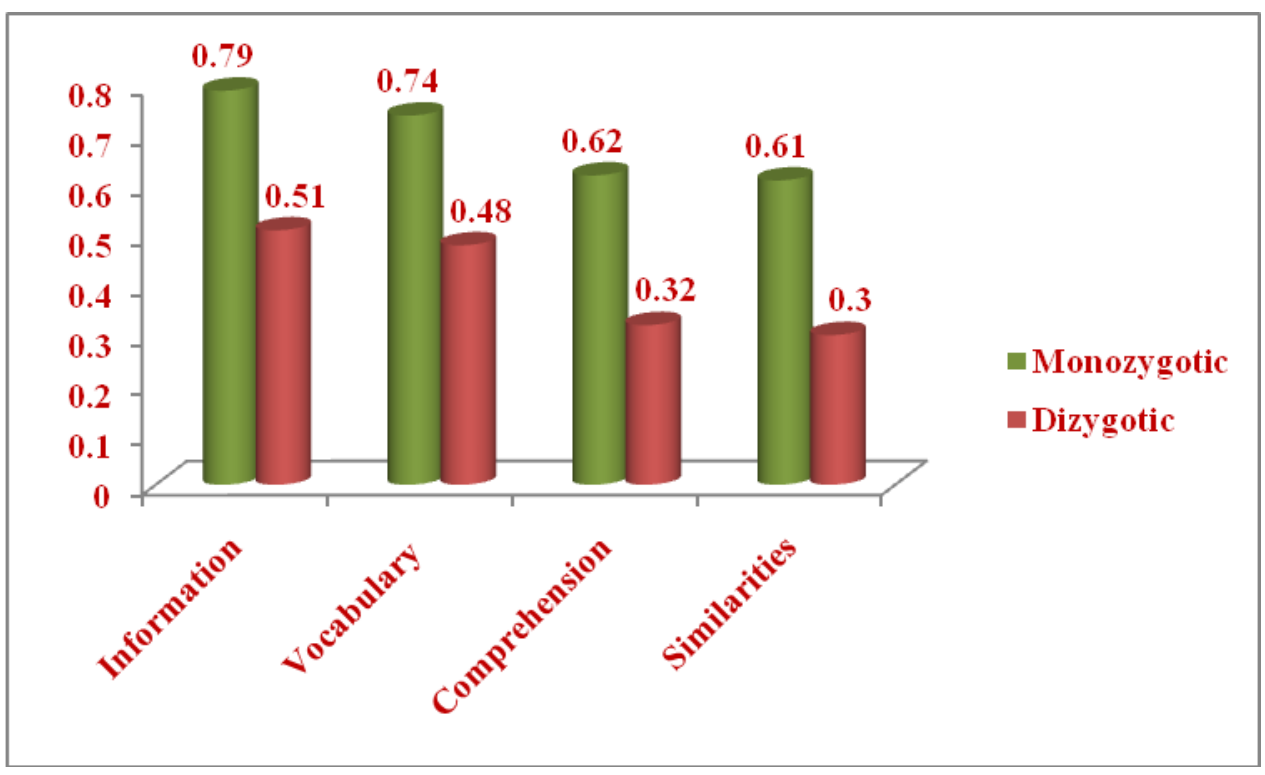

Fig.2 Heritability estimates for verbal aspects

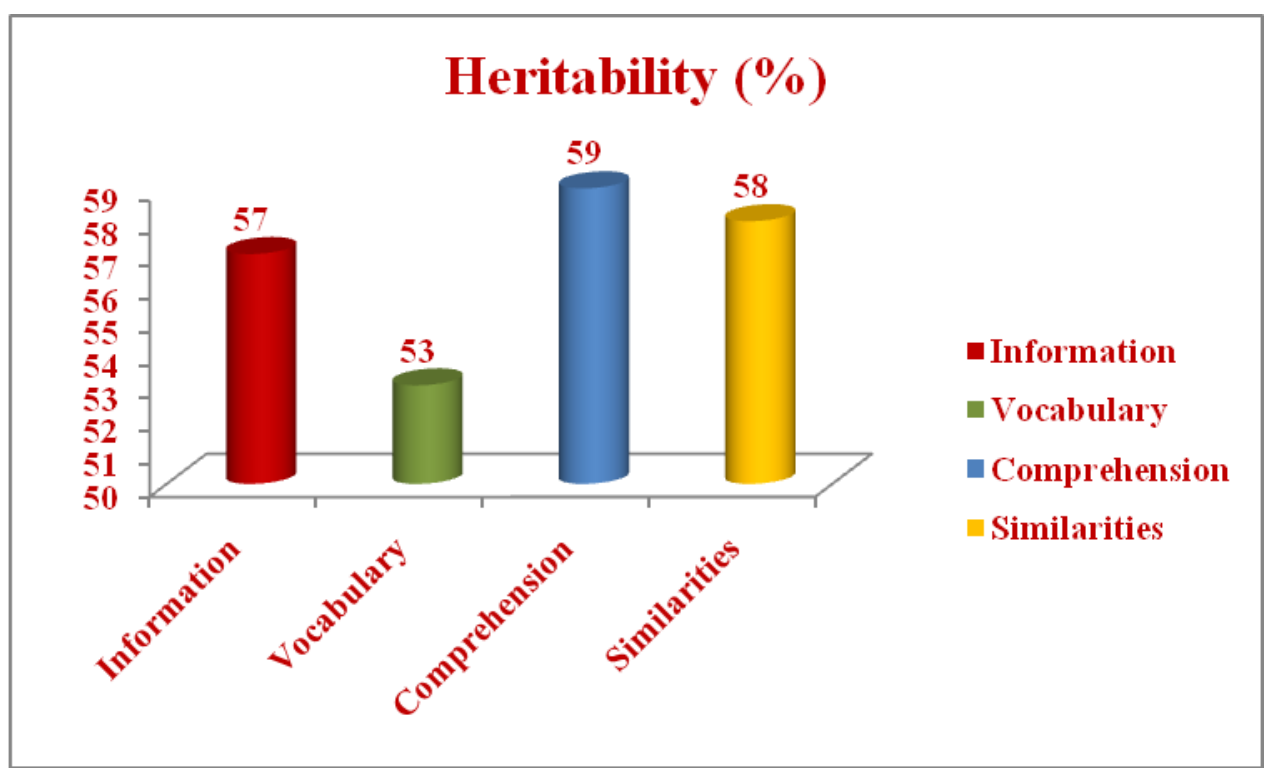




\section{References}

Anokhin, A. P., Golosheykin, S., Grant, J. D. and Heath, A. C. (2017). Heritability of brain activity related to response inhibition: a longitudinal genetic study in adolescent twins. Int $J$ Psychophysiol, 115, 112-124.

Bradley, R. H., Caldwell, B. M., Rock, S. L., Hamrick, H. M., and Harris, P. (1988). Home observation for Measurement of the Environment: Development of a Home Inventory for Use with Families having Children 6 to 10 Years Old. Contemporary Educational Psychology, 13, 58-71.

Elliot, M., Tucker-Drob, Briley, D. A. and Harden, K. P. (2013). Genetic and environmental influences on cognition across development and context. Current Dir. Psychological Science, 22(5), 349-355.

Wechsler, D. 1974. Wechsler Intelligence Scale for Children (revised edition). New York: The Psychological Corporation, 1-191.

Van Dongen, J., Slagboom, P.E., Draisma, H.H., Martin, N. G., and Boomsma,
D.I. (2012). The continuing value of twin studies in the omics era. Nat Rev Genet., 13(9), 640-653.

Johnson, W., Turkheimer, E., Gottesman, I. I., and Bouchard, T. J. (2010). Beyond Heritability: Twin Studies in Behavioral Research. Curr. Dir. Psychol. Sci., 18(4): 217-220.

Fowler, J. H., Baker, L. A., and Dawes, C. T. (2008). Genetic variation in political participation. American Political Science Review, 102: 233-248.

Plutzer, E. (2002), Inertia, resources, and growth in young adulthood. American Political Science Review, 96: 41-56.

Rosalind, Y, Z., Rijsdijk and Corley, R. (2018). Differential environmental influences on the development of cognitive abilities during childhood, intelligence. Elsevier, 66(C), 26-39.

Spengler, M. Gottschling, J., Hahn, E., Tucker-Drob, E. M., Harzer, C. and Spinath, F. M. (2018). Does the heritability of cognitive abilities vary as a function of parental education? Evidence from a German twin sample. PLoS ONE, 13(5).

\section{How to cite this article:}

Annu and Bimla Dhanda. 2019. Genetic and Environmental Influences on Verbal Aspects of Twins. Int.J.Curr.Microbiol.App.Sci. 8(11): 1517-1521. doi: https://doi.org/10.20546/ijcmas.2019.811.176 